\title{
Testing for the Disposition Effect on Optimal Stopping Decisions
}

\author{
Jacopo Magnani
}

Online Appendix

\section{Instructions}

You are about to participate in an experiment in the economics of decision-making. The National Science Foundation and other agencies have provided the funding for this project. If you follow these instructions carefully and make good decisions, you can earn a CONSIDERABLE AMOUNT OF MONEY, which will be PAID TO YOU IN CASH at the end of the experiment.

Your computer screen will display useful information. Remember that the information on your computer screen is private. To insure best results for yourself and accurate data for the experimenters, please do not communicate with the other participants at any point during the experiment. If you have any questions, or need assistance of any kind, raise your hand and one of the experimenters will come.

\section{Rounds}

The experiment will be divided into a number of rounds. The length of a round will be random - you will never know how long a round will last or when it is about to end (details below). Decisions and points made in one round do not affect other rounds. There will be around 35 rounds.

\section{The Basic Idea}

You are an investor in a financial market where an asset is traded. Each round you start the game with some cash with which you can buy shares of a stock. After you have bought the shares, the stock price will change randomly over time. At that point, your only decision is when, if ever, to sell your shares.

\section{Buying}

At the beginning of each round you will be given 100 units of cash. In the first stage of the round you can decide to use your cash to buy shares of a stock at a given price per share. You can choose to spend up to and no more than the 100 units of cash, but you will have to buy at least one share. After you have made this choice (or after 20 seconds have passed), the stock price will start changing over time.

\section{Selling}

At any moment you can decide to sell the stock to cash its value. After you have sold your stock, you cannot sell or buy anymore before a new round starts. Whenever you choose to sell, you will be guaranteed to obtain at least a value of $X$, no matter how low is the stock price. More exactly points when you sell are determined in the following way:

1. If the price of the stock is above $X$ and you sell, you will be paid an amount of points exactly equal to the price of the stock for each of your shares 
2. If the price of the stock is below $X$ and you sell, you will be paid $X$ for each of your shares.

For example, assume you have 5 shares and $X$ is 4 . If the current stock price is 12 and you sell, you cash the stock price and earn $12 \times 5=60$ points. If the stock price is 2 and you sell, you will earn 4 points per share (instead of 2 points), for a total of $4 \times 5=20$. See the details below for the exact value of $X$ that we will use in this experiment.

\section{Holding on to the stock}

What if you have not sold your stock when the round randomly ends? One of the following will occur:

1. Normal Ending: You are paid the current stock price for each share you hold (even if the price is below $X$ ) or

2. Stock Expiration: The opportunity to sell the stock evaporates and you receive no points from your investment in the stock.

The computer will randomly decide which of these occurs when the round ends (details below).

Figure 1: Screen example

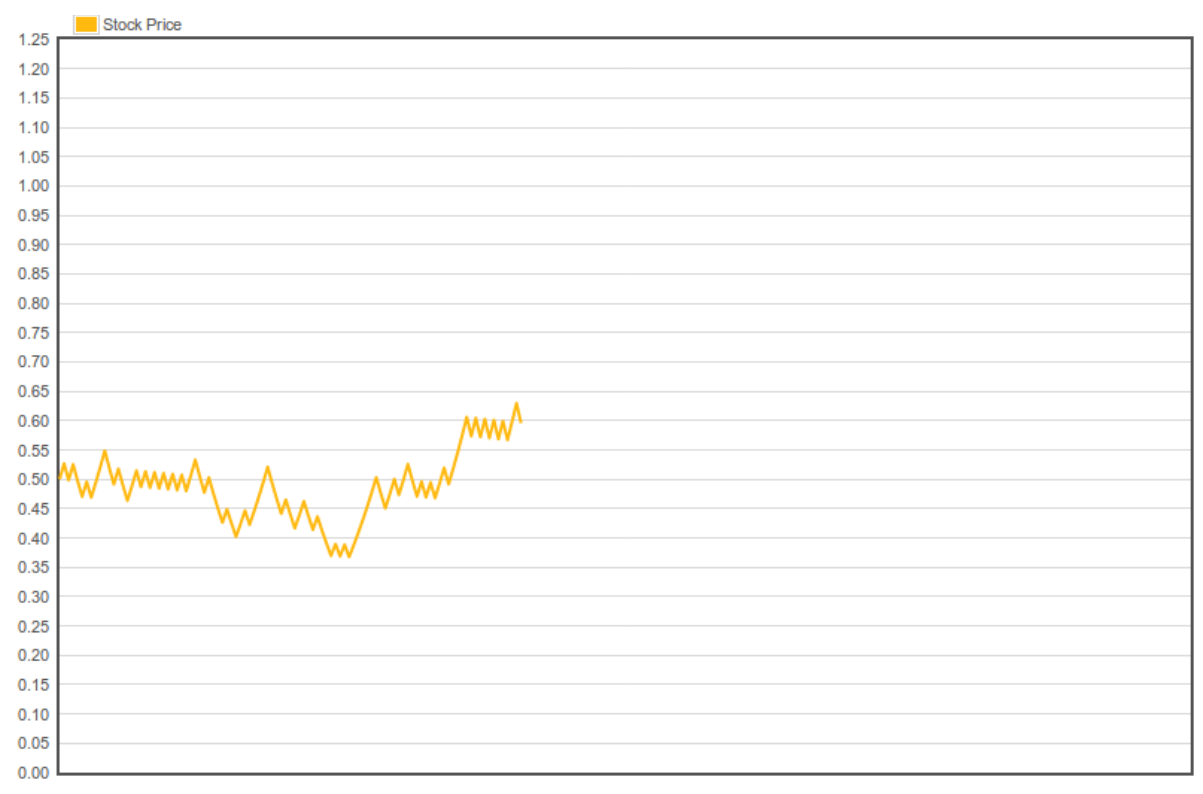

\section{Screen Information}

The screenshot shows an example of the screen you will see during each round.

The plot shows you the stock price as a yellow line. The rightmost tip (the leading edge) of each shows what is happening right now. 
At any moment you can sell your asset by clicking the button at the bottom of the screen that says Sell. However remember that after you click on it the button will be disabled for the rest of the round.

\section{Feedback}

After the round is over, you will be shown a summary message in your page repeating your score, your action and whether the stock expired at the end of the round. The break between rounds will last around 20 seconds.

\section{Earnings}

At the end of each round, your score for that round will be given by the amount of cash you have not invested in the stock plus the points you received from your investment in the stock.

Points are converted into dollars according to the following formula: one hundred points are equal to 25 cents.

At the end of the last round, your earnings will be determined by summing the points for all rounds, applying the conversion into dollars and adding a $\$ 5$ show-up fee. For example, if your points over all the rounds are 3500 , then your payment is $3500 \times \$ 0.25 / 100+\$ 5=\$ 8.75+\$ 5=\$ 13.75$.

\section{Details}

Here are a few more details on the experiment, in case you want to know.

What are the exact values of $X$ and the purchase stock price?

- At the beginning of each round the stock price is 10 .

- The minimum score you can get by selling will be $X=10$

How fast will the game be played?

- Time within each round is measured in ticks. A tick occurs 5 times in a second.

Here are some details on how the stock price unfolds:

- the price is updated every tick (5 times every second)

- each tick the price moves randomly up or down by a fixed percentage, around $5 \%$.

- upticks are as likely as downticks

How long will a round last?

- The round length is random. The round ends with a small probability each tick, $\frac{1}{5}$ of $1 \%$.

- The average length of a round is around 1 minute and a half. Many rounds will last less than the average, and a few will last much longer.

- Rounds longer than 10 minutes are so unlikely that you probably will never see one.

- The minimum length is one tick, but it is unlikely you will ever see a round quite that short

How often will rounds end in the stock expiring?

- On average, around $45 \%$ of the rounds will end in the stock expiring. 


\section{Frequently Asked Questions}

Q1. Is this some kind of psychology experiment with an agenda you haven't told us?

Answer: No. It is an economics experiment. If we do anything deceptive, or don't pay you cash as described, then you can complain to the campus Human Subjects Committee and we will be in serious trouble. These instructions are meant to clarify how you earn money, and our interest is in seeing how people make investment timing decisions. 